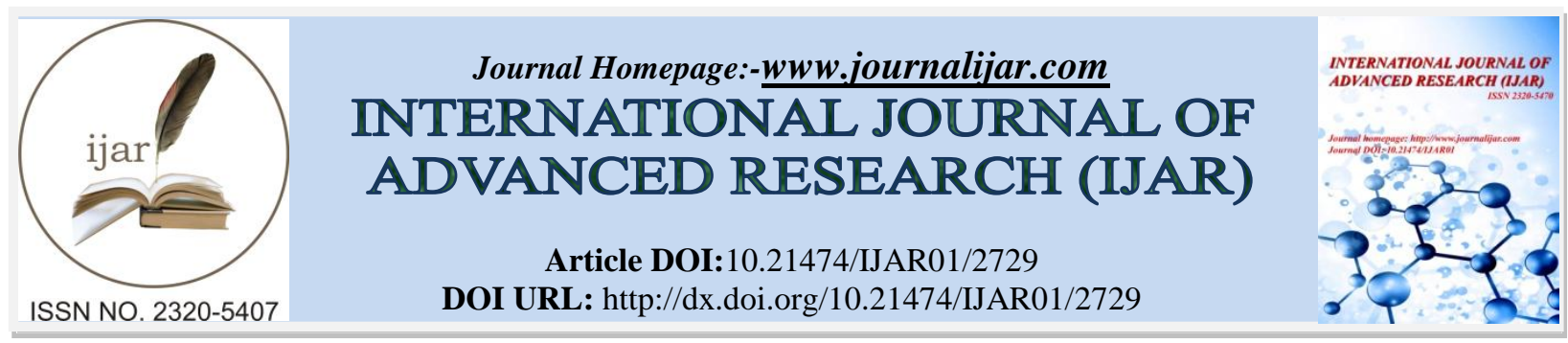

RESEARCH ARTICLE

\title{
RADIOMORPHOMETRIC INDICES AND THEIR RELATION TO ALVEOLAR BONE LOSS IN COMPLETELY EDENTULOUS PATIENTS: A PROSPECTIVE STUDY.
}

\section{Dr. Neha Vaidya MDS', Dr. Amarnath G S MDS², Dr. B C Muddugangadhar MDS, PGCDI, DHM Dr. Poonam RaoT $\mathbf{R}^{4}$ and Dr. Vishal Seth MDS 5 .}

1. Reader, Department of Prosthodontics, Himachal Dental College, Sundernagar, H.P.

2. Professor and Head, Department of Prosthodontics, M R Ambedkar Dental College \& Hospital, \#1/36, Cline Road, Cooke Town, Bengaluru, Karnataka-560005.

3. Professor, Department of Prosthodontics, M R Ambedkar Dental College \& Hospital, Bengaluru.

4. Post Graduate student, Department of Prosthodontics, M R Ambedkar Dental College \& Hospital, Bengaluru.

5. Reader, Department of Orthodontics, Himachal Dental College, Sundernagar, H.P.

\section{Manuscript Info}

\section{Manuscript History}

Received: 15 November 2016

Final Accepted: 17 December 2016

Published: January 2017

\section{Keywords:}

Radiomorphometric, edentulous patients, alveolar, panoramic radiograph

\section{Abstract}

Statement of problem: In edentulous patients, alveolar bone loss is a critical factor that affects denture retention, stability, and masticatory function.

Purpose: To investigate the influence of age and gender on the mandibular cortical index, panoramic mandibular index, and mandibular cortical width, as well as alveolar bone loss and bone heights in the first premolar and molar region using panoramic radiographs of edentulous patients.

Material and methods: Panoramic radiographs of 75 edentulous patients were assessed. In addition to gender and age, the mandibular cortical index, panoramic mandibular index, mandibular cortical width at the mental foramen region, alveolar bone loss, and bone heights of the premolar and molar regions of the mandible were recorded. Statistical comparisons were performed using chi-square and 2-way ANOVA tests.

Results: Of the 75 patients, $32(42 \%)$ were men and $43(57.3 \%)$ were women. The association between MCI and age group was not statistically significant in males $(\mathrm{P}>0.05)$. In females, the association between MCI and age group was found to be statistically significant $(\mathrm{P}<0.01)$. The difference between males and females with respect to mean $\mathrm{MCW}$ is found to be statistically significant $(\mathrm{P}<0.001)$ indicating that gender is a significant factor influencing $\mathrm{MCW}$.

Conclusions:The values of mean cortical width (MCW) at the mental foramen region decreased significantly with age in women $(\mathrm{P}<0.001)$. The ratio of the thickness of the mandibular cortex to the distance between the mental foramen and the inferior mandibular cortex (PMI) was not affected by gender or age.

Copy Right, IJAR, 2016,. All rights reserved.

Corresponding Author:- Dr. NehaVaidya MDS.

Address:- Reader, Department of Prosthodontics, Himachal Dental College, Sundernagar, H.P. 


\section{Introduction:-}

In many phases of prosthetic dentistry, healthy alveolar bone with normal regenerative capacity is essential for a successful treatment outcome. It is important to know the quantity and quality of bone in the jaws when planning prosthetic and pre-prosthetic surgical treatment. The residual ridge influences gingival esthetics and pontic dimensions ${ }^{1}$ for fixed partial dentures; it provides support and stability for removable partial dentures and complete dentures; and the underlying bone is a prerequisite for the placement of oral implants. Resorption of residual ridges is a complex biophysical process ${ }^{2}$ and is widely recognized as one of the most important factors affecting denture support, retention, stability and masticatory function in edentulous patients. ${ }^{3}$

Reduction of the residual alveolar ridges could be described as a resorptive atrophy, a physiologic reaction to loss of function and inactivity. ${ }^{4}$ After dental extractions, the residual alveolar bone undergoes a period of accelerated resorption for about 10 weeks, followed by a slower, but progressive resorption thereafter. ${ }^{5,6}$ Due to its progressive nature, the height of the alveolar ridge and basal bone will decrease, ${ }^{6,7}$ resulting in alveolar ridge bone loss as great as $1 \mathrm{~mm}$ per year in complete denture wearers., ${ }^{8,9}$ Loss of alveolar bone from an edentulous ridge is more pronounced in the mandible than the maxilla, ${ }^{10}$ particularly in the early 3 months of post extraction period. ${ }^{11,12}$

Age related mandibular bone loss may be due to general thinning and increased porosity of the mandibular cortex. Bone loss occurs more rapidly in the premolar and molar regions of the edentulous mandible, compared to the anterior region. Therefore, bone resorption of the basal bone is more frequent in this region. ${ }^{13}$ Most state that women have more advanced bone loss than men, but some have not found such a difference. ${ }^{14-16}$

Previous investigations on the effects of radiomorphometric indices and alveolar bone loss (ABL) have focused primarily on partially or completely dentate women. ${ }^{17-21}$ Accordingly, it is logical to assume that a possible relationship exists among bone loss, radiomorphometric indices, and edentulism. The panoramic projection (pantomograph) is a commonly used radiographic view in all disciplines of dentistry, methods of quantifying alveolar bone loss on panoramic films is of great value, particularly in clinical studies. ${ }^{22}$ Several authors have attempted to measure and quantify mandibular alveolar bone loss radiographically, most of these studies have used lateral cephalometric radiographs. ${ }^{23,24}$ However, the use of lateral cephalograms for this purpose may involve a fairly large error. ${ }^{23}$

A number of qualitative and quantitative indices, including the mandibular cortical index (MCI), mandibular cortical width $(\mathrm{MCW})$, or panoramic mandibular index (PMI), have been used to assess bone quality and to observe signs of resorption on panoramic radiographs. ${ }^{18,19}$

In light of these observations, the purpose of this study is to investigate the influence of age and gender on the mandibular cortical index, panoramic mandibular index, and mandibular cortical width, as well as alveolar bone loss and bone height using panoramic radiographs of edentulous patients.

\section{Materials and Method:-}

Source of data: Subjects with completely edentulous maxillary and mandibular ridges in the age group of 50 to 80 years visiting the Department of Prosthodontics at M R Ambedkar Dental College \& Hospital, Bengaluru.

\section{Method of collection of data:-}

The study consists of 75 individuals in the age group of 50 to 80 years which are divided into 2 groups i.e., $\leq 60$ and $>60$ years. Intraoral examination was performed for selection of study subjects.

\section{Inclusion criteria:-}

1. Completely edentulous subjects without root stumps.

2. Subjects without any systemic illness.

\section{Exclusion criteria:-}

1. Subjects suffering from diabetes. 
2. Previous history of usage of dentures.

3. Subjects suffering from endocrine disorders.

A written consent was obtained from the subjects selected to be a part of the study and they were explained in detail about the procedure which was carried out. Each subject was made to stand comfortably and the patients maxillary and mandibular jaws were placed within the focal trough of the digital panoramic machine stably and digital panoramic radiographs were obtained. All panoramic images were made with the same digital panoramic radiography unit i.e. Kodak 8000 c digital and cephalometric system (Made in France - 2006).

Gender and age were recorded for each patient. Linear measurements on panoramic images were made using imaging software i.e., TrophyDicom at a correction for $1.27 \%$ magnification. The total duration of study was 1 year 6 months.

The measurements for radiomorphometric indices which included mandibular cortical index (MCI), mandibular cortical width (MCW), panoramic mandibular index (PMI), as well as alveolar bone loss (ABL) and heights in the first premolar and molar region ( $\mathrm{Hp}$ and $\mathrm{Hm}$ ) were performed.

\title{
Mandibular cortical index (MCI):-
}

Mandibular cortical index (MCI) refers to the inferior mandibular cortical thickness and is categorized into the following 3 groups according to the criteria described by Klemettiet al. ${ }^{17}$ :

$\mathrm{C} 1$ : the endosteal margin of the cortex is even and sharp on both sides

C2: the endosteal margin shows semilunar defects (lacunar resorption) and/or seems to form endosteal cortical residues on one or both sides and

C3: the cortical layer forms heavy endosteal cortical residues and is clearly porous.

\section{Mandibular cortical width (MCW):-}

Mandibular cortical width is the measurement of the cortical width at the mental foramen region and is assessed according to the technique described by Ledgertonet al. ${ }^{38}$ in which the mental foramen is identified and a line is traced which passes perpendicular to the tangent of the lower border of the mandible and through the center of the mental foramen. The cortical width is measured at this point.

\section{Panoramic mandibular index (PMI):-}

The Panoramic mandibular index (PMI) as described by Benson et al. ${ }^{29}$ is the ratio of the thickness of the mandibular cortex to the distance between the mental foramen and the inferior mandibular cortex.

\begin{abstract}
Alveolar bone loss (ABL):-
Alveolar bone $\operatorname{loss}^{54}(\mathrm{ABL})$ of the mandible is the ratio of the radiographic mandibular total bone height to the height from the center of the mental foramen to the inferior border of the mandible. The mandibular total bone height (TBH) and basal bone height (BBH; height from the centre of the mental foramen to the inferior border of the mandible) at the site of the mental foramen were measured bilaterally. Mean TBH/BBH ratio on both sides was defined as the degree of alveolar bone loss of the mandible.
\end{abstract}

\section{Heights in the first premolar and molar region (Hp and Hm):-}

Heights in the first premolar and molar region were measured according to measurement locations described by Guleret al. ${ }^{46}$ i.e., by drawing a line tangential to the most inferior points at the mandibular angle and the lower border of the mandibular body. Horizontal lengths of the mandible were measured parallel to the tangent at $10 \mathrm{~mm}$ above the lower border of the mandible. According to results from the dentate subjects, the first premolar and the first molar were located approximately 35 and $55 \%$, respectively, of the length of the mandibular body from the midline. The measurements Y1 (midline), Y2 (mandibular first premolar) and Y3 (mandibular first molar) were vertical distances from the interior border of mandible to the alveolar crest.

\section{Statistical Analysis:-}

The obtained data will be calculated and subjected to relevant statistical analysis using chi-square and 2-way ANOVA tests for proportions. 


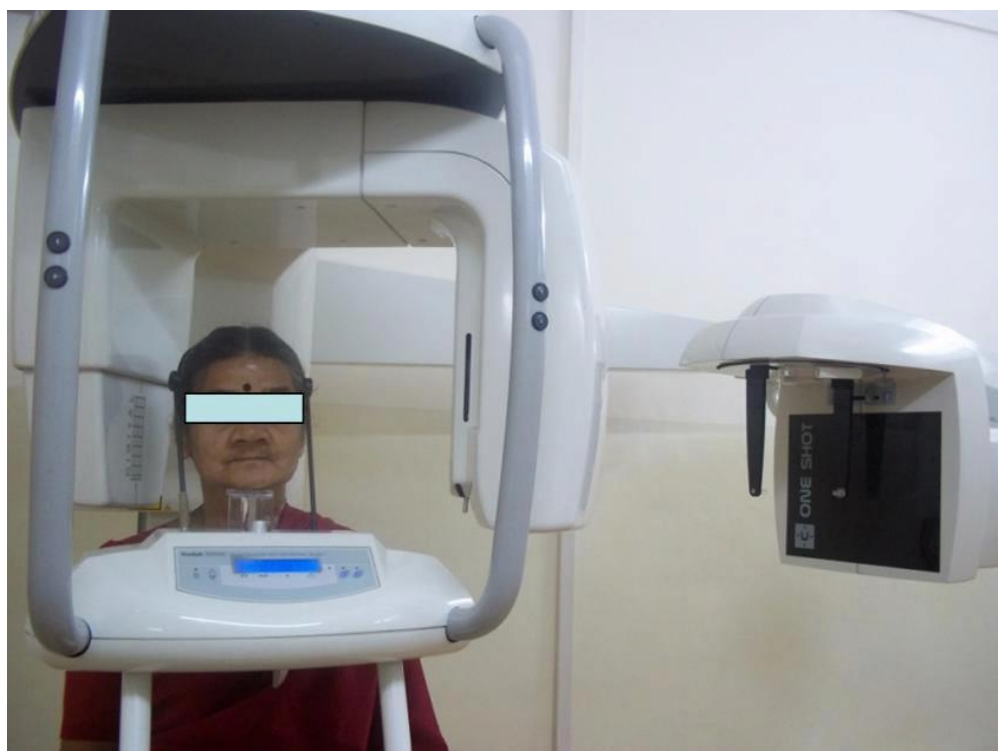

Figure 1:- Digital Panoramic Machine

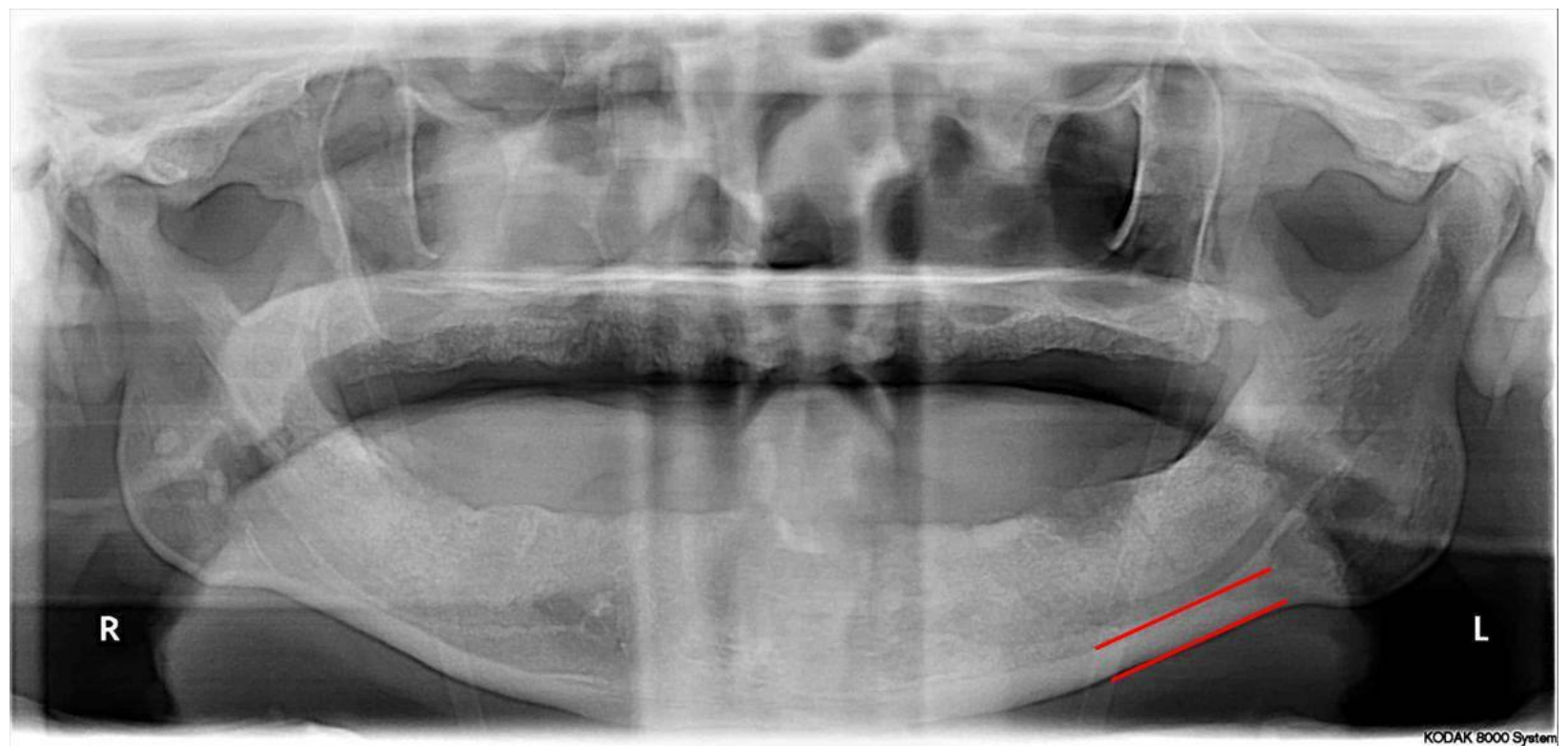

Figure 2:- C1 Category of Mandibular cortical Index (MCI) 


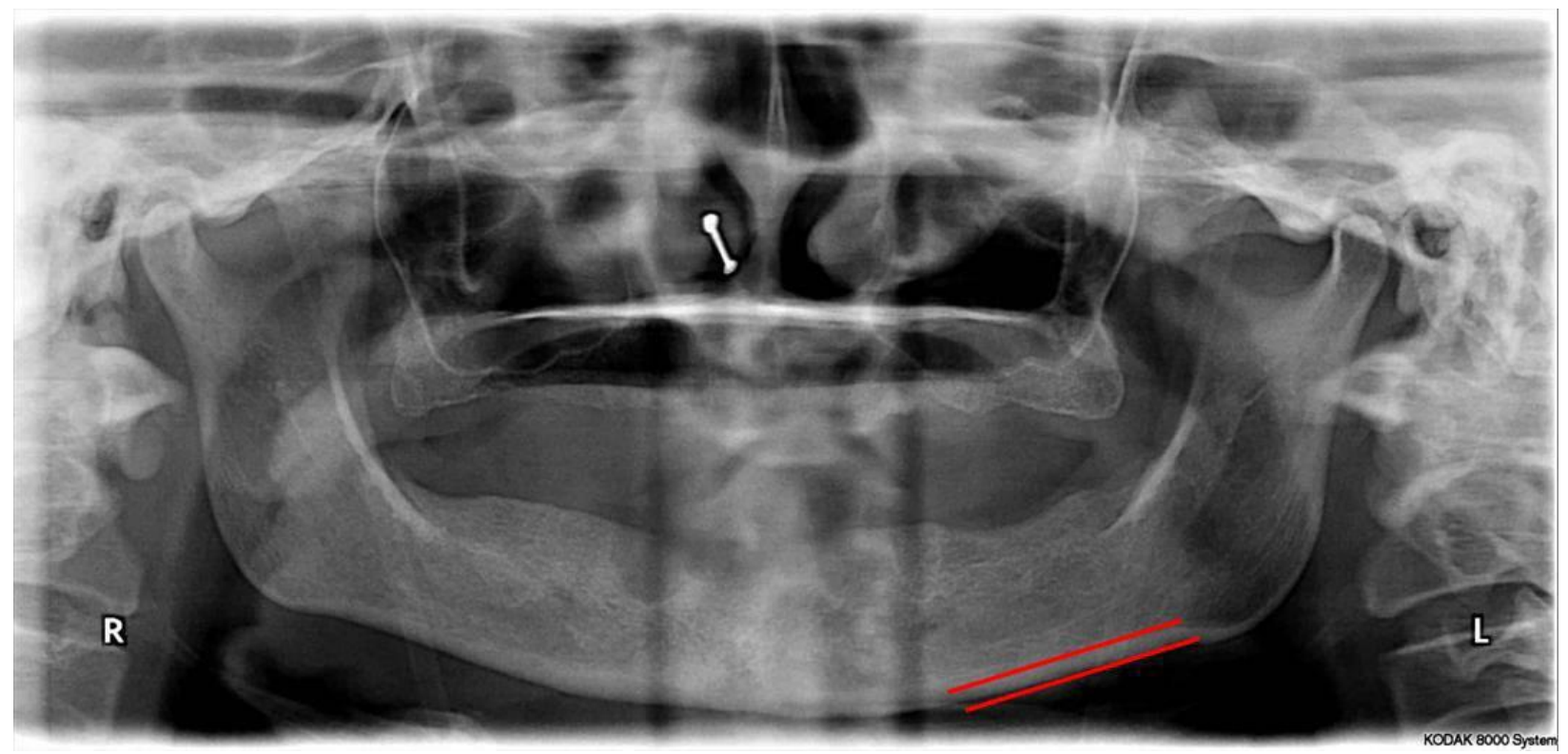

Figure 3:- C2 Category of Mandibular cortical Index (MCI)

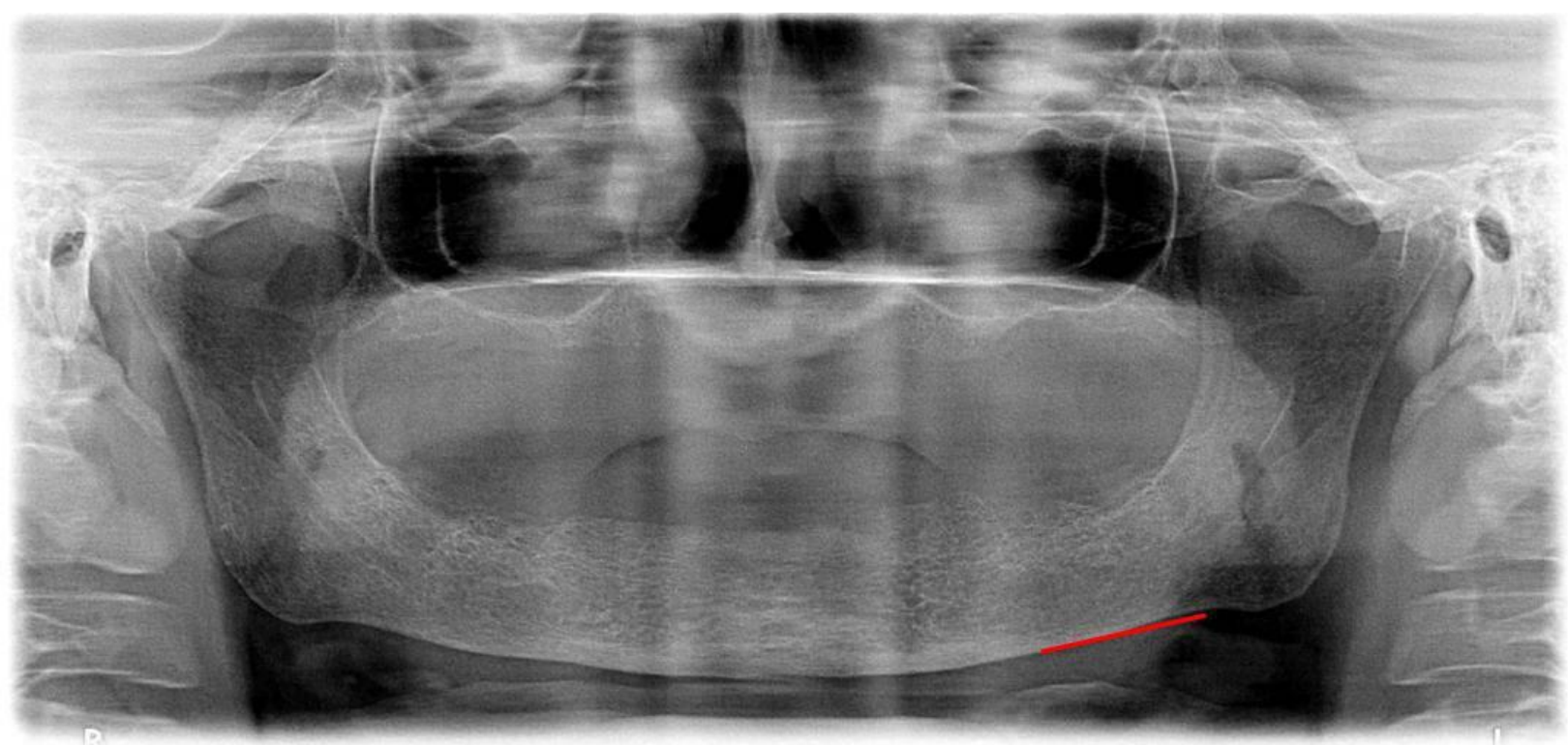

Figure 4:- C3 Category of Mandibular cortical Index (MCI) 


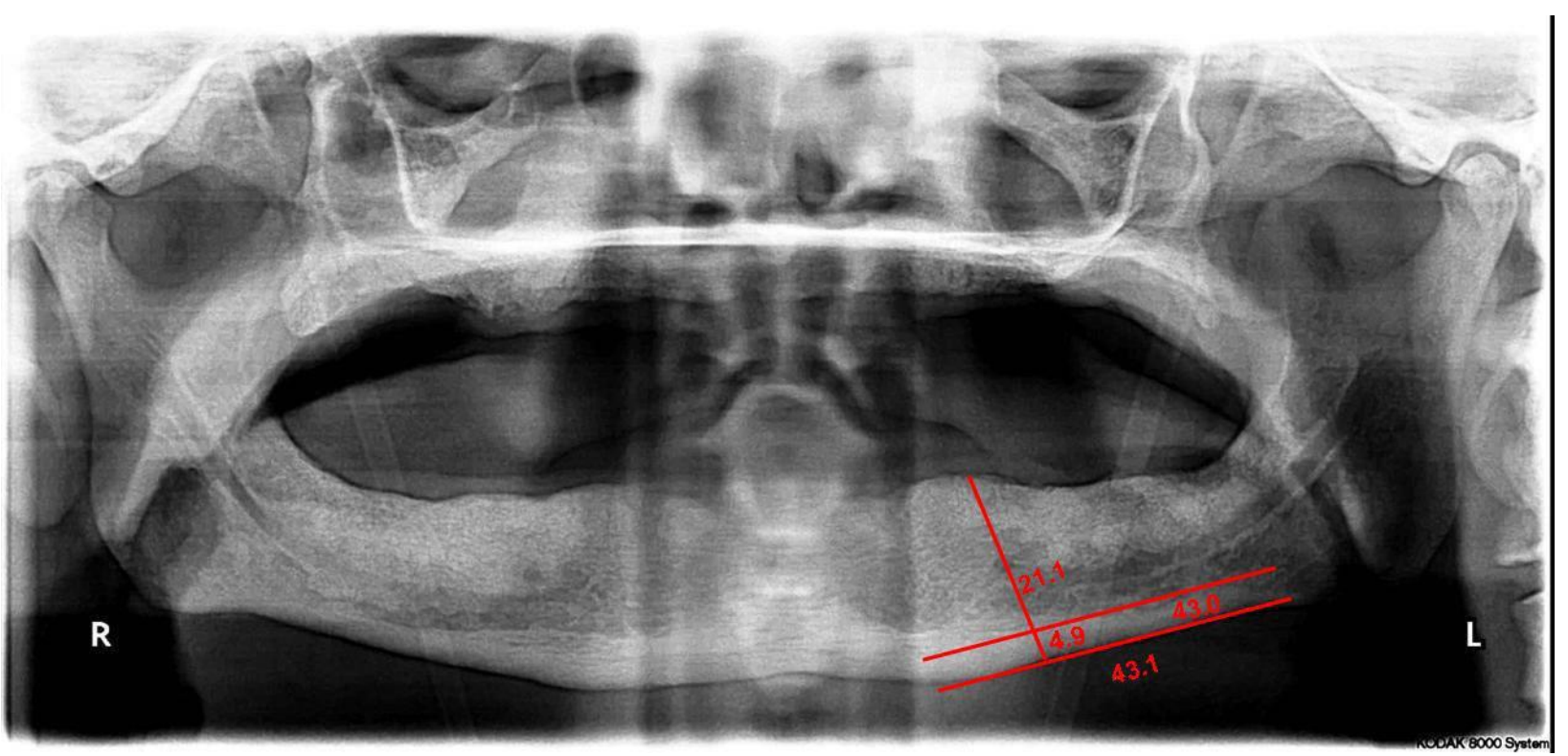

Figure 5:- Mandibular Cortical Width (MCW); The distance between the two parallel lines is the MCW

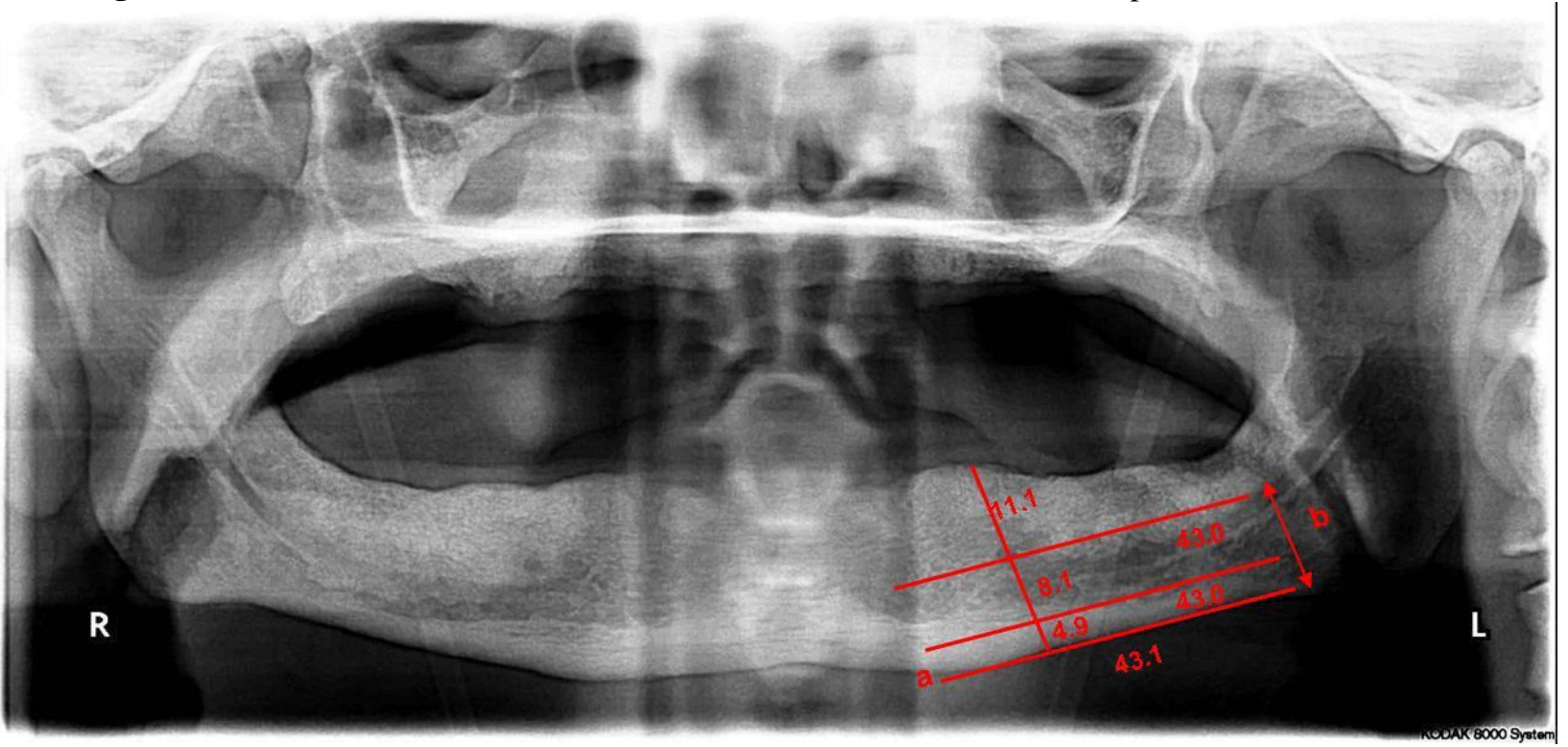

Figure 6:- Panoramic Mandibular Index (PMI) 


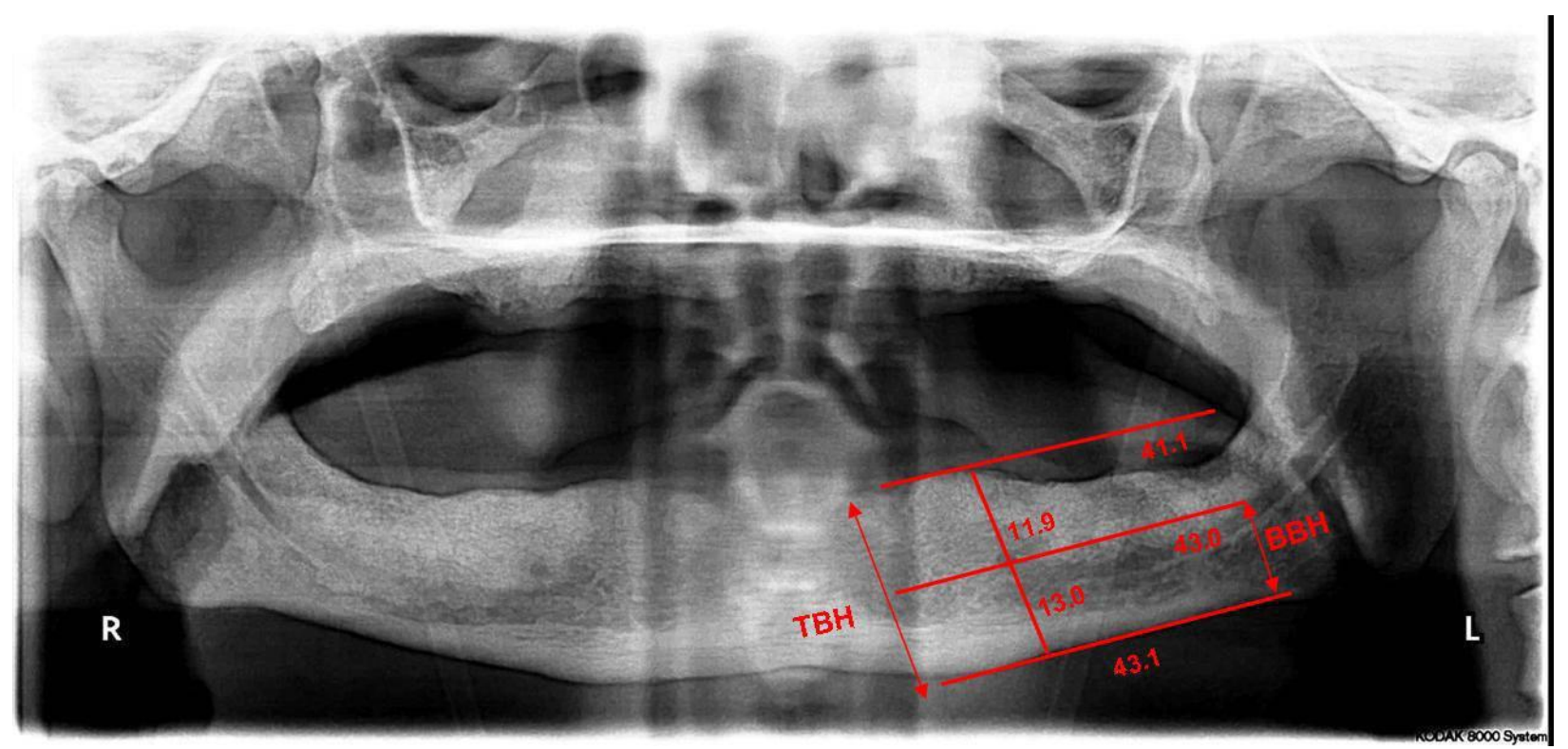

Figure 7:- Alveolar Bone Loss (ABL)

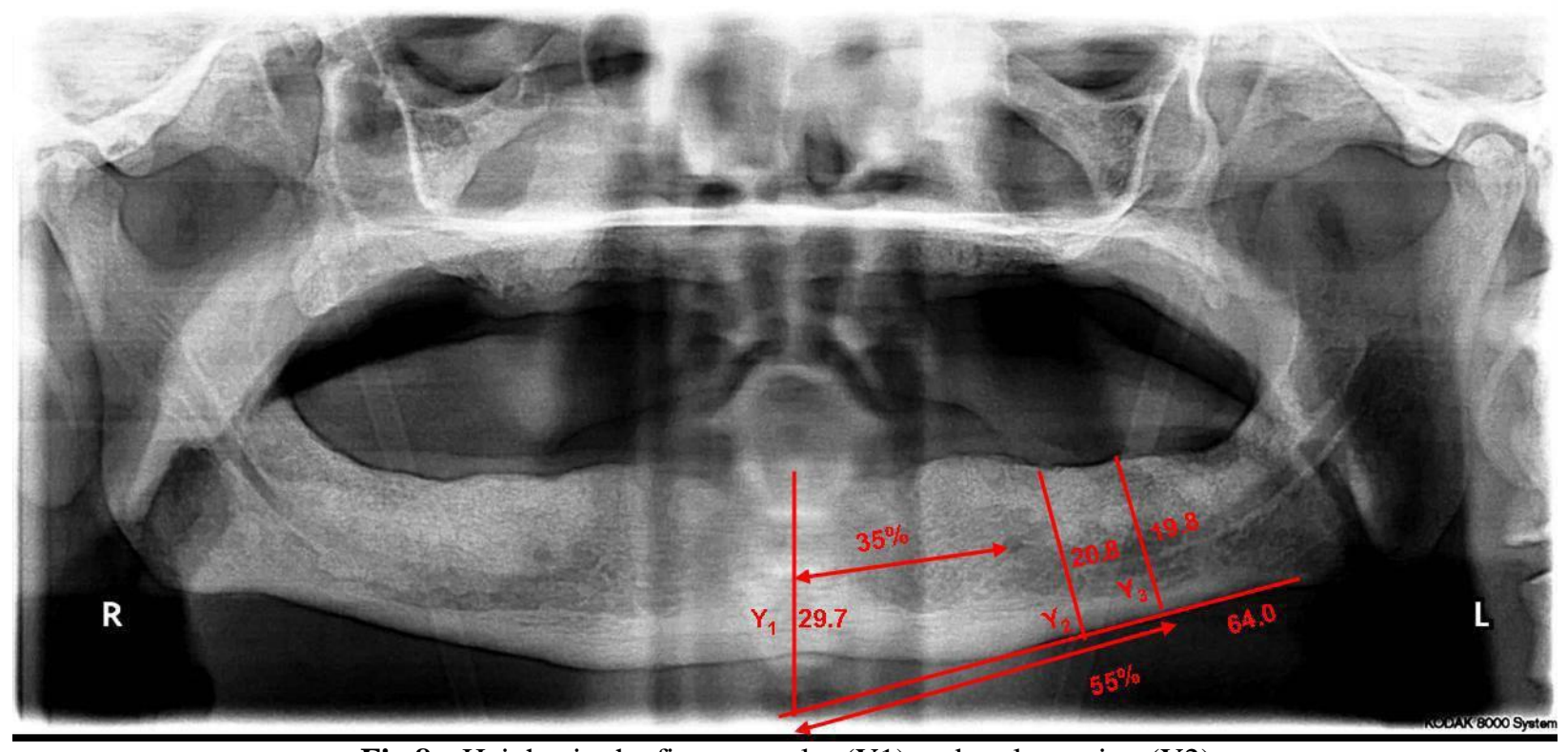

Fig 8:- Heights in the first premolar (Y1) and molar region (Y2)

\section{Results:-}

In the present study, digital panoramic radiographs of subjects with completely edentulous maxillary and mandibular ridges in the age group of 50 to 80 years were studied to investigate the influence of age and gender on the mandibular cortical index, panoramic mandibular index, and mandibular cortical width, as well as alveolar bone loss and bone height in first premolar and molar region.

Of the 75 patients, $32(42 \%)$ were men and $43(57.3 \%)$ were women. Only 2 categories of MCI (C2 and C3) were detected. The association between MCI and age group was not statistically significant in males $(\mathrm{P}>0.05)$. 
In females, the association between MCI and age group was found to be statistically significant $(\mathrm{P}<0.01)$. Females in $\leq 60$ years age group were found to be more associated with $\mathrm{C} 2$ whereas females in $>60$ years age group were found to be more associated with C3. (Table No. 1 and 2)

The difference between males and females with respect to mean $\mathrm{MCW}$ is found to be statistically significant $(\mathrm{P}<0.001)$ indicating that gender is a significant factor influencing $\mathrm{MCW}$. However, age group is not a significant factor influencing $\mathrm{MCW}(\mathrm{P}>0.05)$ and the interaction (joint effect) of gender and age group on $\mathrm{MCW}$ is not statistically significant $(\mathrm{P}>0.05)$. (Table No. 3 to Table No.7)

Neither gender nor age group or the interaction of gender and age group are found to be significantly influencing PMI. (Table No. 3 to Table No.7) Statistically significant difference is observed between males and females with respect to alveolar bone loss. The difference between the two age groups is also found to be statistically significant in females but not in males. (Table No. 3 to Table No.7)

Statistically significant difference is observed between males and females with respect to mean height of premolar $(\mathrm{P}<0.01)$. The difference between the two age groups is also found to be statistically significant $(\mathrm{P}<0.01)$. But the interaction of gender and age group on height of premolar is not statistically significant $(\mathrm{P}>0.05)$. This shows that gender and age group individually influence the height of premolar. (Table No. 3 to Table No.7)

Statistically significant difference is observed between males and females with respect to mean height of molar $(\mathrm{P}<0.01)$. The difference between the two age groups is also found to be statistically significant $(\mathrm{P}<0.01)$. But the interaction of gender and age group on height of molar is not statistically significant $(\mathrm{P}>0.05)$. This shows that gender and age group individually influence the height of molar. (Table No. 3 to Table No.7)

Table 1:- Comparison of Age group and MCI

\begin{tabular}{|c|c|c|c|c|c|c|c|c|}
\hline \multirow[t]{2}{*}{ Gender } & \multirow[t]{2}{*}{ Age group } & \multicolumn{2}{|l|}{$\mathrm{C} 2$} & \multicolumn{2}{|c|}{ C3 } & \multirow[t]{2}{*}{ Total } & \multirow[t]{2}{*}{$X^{2}$} & \multirow[t]{2}{*}{ P Value } \\
\hline & & $\mathrm{n}$ & $\%$ & $\mathrm{n}$ & $\%$ & & & \\
\hline \multirow[t]{2}{*}{ Male } & $\leq 60$ yrs & 7 & 78 & 2 & 22 & 9 & \multirow[b]{2}{*}{2.358} & \multirow[b]{2}{*}{0.125} \\
\hline & $>60 \mathrm{yrs}$ & 11 & 48 & 12 & 52 & 23 & & \\
\hline \multirow[t]{2}{*}{ Female } & $\leq 60 \mathrm{yrs}$ & 14 & 88 & 2 & 13 & 16 & \multirow[b]{2}{*}{11.848} & \multirow[b]{2}{*}{$0.001 *$} \\
\hline & $>60 \mathrm{yrs}$ & 9 & 33 & 18 & 67 & 27 & & \\
\hline
\end{tabular}

*de notes significant association

Table 2:- Distribution (\%) of mandibular cortical index (MCI) classifications (category C2, mild erosions; category $\mathrm{C} 3$, severe erosions on endosteal margin of mandible)according to Age and Gender.

\begin{tabular}{|c|c|c|}
\hline Males & C2 (in \%) & C3 (in \%) \\
\hline 60 years & 78 & 22 \\
\hline$>$ 60 years & 48 & C3 (in \%) \\
\hline Females & C2 (in \%) & 13 \\
\hline 60 years & 88 & 67 \\
\hline
\end{tabular}

Table 3:- Mean of various parameters according to Gender.

\begin{tabular}{|c|c|c|c|c|c|c|}
\hline Parameter & Gender & Mean & SD & Median & Min & Max \\
\hline \multirow{2}{*}{ MCW } & Male & 4.23 & 0.67 & 4.15 & 2.80 & 5.50 \\
\cline { 2 - 7 } & Female & 3.51 & 0.85 & 3.60 & 2.00 & 4.80 \\
\hline \multirow{2}{*}{ PMI } & Male & 0.31 & 0.04 & 0.31 & 0.22 & 0.40 \\
\cline { 2 - 7 } & Female & 0.29 & 0.06 & 0.28 & 0.17 & 0.48 \\
\hline \multirow{2}{*}{ ABL } & Male & 1.89 & 0.20 & 1.83 & 1.60 & 2.40 \\
\cline { 2 - 7 } & Female & 1.99 & 0.06 & 1.99 & 1.81 & 2.08 \\
\hline \multirow{2}{*}{\begin{tabular}{c} 
Height of \\
\cline { 2 - 7 }
\end{tabular}} & Male & 25.93 & 3.00 & 26.20 & 17.10 & 31.00 \\
\hline \multirow{2}{*}{$\begin{array}{c}\text { Height of } \\
\text { molar }\end{array}$} & Female & 23.28 & 3.31 & 23.00 & 16.00 & 28.50 \\
\cline { 2 - 7 } & Male & 24.43 & 3.07 & 24.90 & 14.30 & 29.50 \\
\hline
\end{tabular}


Table 4:- Mean of various parameters according to Age group

\begin{tabular}{|l|l|l|l|l|l|l|}
\hline Parameter & Age group & Mean & SD & Median & Min & Max \\
\hline \multirow{2}{*}{ MCW } & $\leq 60 \mathrm{yrs}$ & 3.99 & 0.78 & 4.10 & 2.00 & 5.50 \\
\cline { 2 - 7 } & $>60 \mathrm{yrs}$ & 3.73 & 0.88 & 3.85 & 2.00 & 5.50 \\
\hline \multirow{2}{*}{ PMI } & $\leq 60 \mathrm{yrs}$ & 0.31 & 0.05 & 0.29 & 0.17 & 0.42 \\
\cline { 2 - 7 } & $>60 \mathrm{yrs}$ & 0.30 & 0.06 & 0.29 & 0.17 & 0.48 \\
\hline \multirow{2}{*}{$\begin{array}{l}\text { HBL } \\
\text { Premolar }\end{array}$} & $\leq 60 \mathrm{yrs}$ & 1.97 & 0.09 & 2.00 & 1.80 & 2.08 \\
\cline { 2 - 8 } & $>60 \mathrm{yrs}$ & 1.90 & 0.15 & 1.91 & 1.60 & 2.40 \\
\hline \multirow{2}{*}{$\begin{array}{l}\text { Height of } \\
\text { Molar }\end{array}$} & $\leq 60 \mathrm{yrs}$ & 25.70 & 3.04 & 26.40 & 16.00 & 29.70 \\
\cline { 2 - 7 } & $>60 \mathrm{yrs}$ & 23.76 & 3.45 & 24.40 & 17.10 & 31.00 \\
\cline { 2 - 7 } & $>60 \mathrm{yrs}$ & 24.47 & 2.93 & 25.10 & 14.70 & 28.30 \\
\hline
\end{tabular}

Table 5:- Mean value of various parameters according to age group within Males

\begin{tabular}{|l|l|l|l|l|l|l|}
\hline Parameter & Age group & Mean & SD & Median & Min & Max \\
\hline \multirow{2}{*}{ MCW } & $\leq 60 \mathrm{yrs}$ & 4.38 & 0.63 & 4.20 & 3.40 & 5.50 \\
\cline { 2 - 7 } & $>60 \mathrm{yrs}$ & 4.17 & 0.69 & 4.10 & 2.80 & 5.50 \\
\hline \multirow{3}{*}{ PMI } & $\leq 60 \mathrm{yrs}$ & 0.31 & 0.03 & 0.31 & 0.26 & 0.37 \\
\cline { 2 - 7 } & $>60 \mathrm{yrs}$ & 0.31 & 0.04 & 0.31 & 0.22 & 0.40 \\
\hline \multirow{2}{*}{$\begin{array}{l}\text { HBL } \\
\text { Premolar }\end{array}$} & $\leq 60 \mathrm{yrs}$ & 1.96 & 0.12 & 2.03 & 1.80 & 2.06 \\
\cline { 2 - 8 } & $>60 \mathrm{yrs}$ & 1.86 & 0.22 & 1.81 & 1.60 & 2.40 \\
\hline \multirow{2}{*}{$\begin{array}{l}\text { Height of } \\
\text { Molar }\end{array}$} & $\leq 60 \mathrm{yrs}$ & 27.22 & 2.34 & 26.70 & 22.40 & 29.70 \\
\cline { 2 - 7 } & $>60 \mathrm{yrs}$ & 25.42 & 3.12 & 25.60 & 17.10 & 31.00 \\
\cline { 2 - 7 } & $>60 \mathrm{yrs}$ & 25.97 & 2.03 & 25.80 & 21.70 & 28.30 \\
\hline
\end{tabular}

Table 6:- Mean value of various parameters according to age group within Females

\begin{tabular}{|l|l|l|l|l|l|l|}
\hline Parameter & Age group & Mean & SD & Median & Min & Max \\
\hline \multirow{2}{*}{ MCW } & $\leq 60$ yrs & 3.78 & 0.78 & 3.95 & 2.00 & 4.70 \\
\cline { 2 - 7 } & $>60$ yrs & 3.35 & 0.86 & 3.50 & 2.00 & 4.80 \\
\hline \multirow{2}{*}{ PMI } & $\leq 60$ yrs & 0.31 & 0.06 & 0.29 & 0.17 & 0.42 \\
\cline { 2 - 8 } & $>60$ yrs & 0.28 & 0.06 & 0.27 & 0.17 & 0.48 \\
\hline \multirow{2}{*}{ ABL } & $\leq 60$ yrs & 1.99 & 0.07 & 1.99 & 1.81 & 2.08 \\
\cline { 2 - 8 } & $>60$ yrs & 1.95 & 0.05 & 1.93 & 1.81 & 2.01 \\
\hline \multirow{2}{*}{$\begin{array}{l}\text { Preight of } \\
\text { Height of } \\
\text { Molar }\end{array}$} & $\leq 60$ yrs & 24.84 & 3.12 & 25.95 & 16.00 & 28.30 \\
\cline { 2 - 8 } & $>60$ yrs & 22.35 & 3.12 & 23.00 & 17.30 & 28.50 \\
\cline { 2 - 8 } & $>60$ yrs & 23.63 & 3.07 & 24.60 & 14.70 & 27.20 \\
\hline
\end{tabular}

Table 7:- Effect of Age \& Gender on different parameters

\begin{tabular}{|l|l|l|l|l|l|}
\hline Parameter & Factor & Sum of squares & Mean & F & P value \\
\hline \multirow{4}{*}{ MCW } & Gender & 7.940 & 7.940 & 13.371 & $<0.001^{*}$ \\
\cline { 2 - 7 } & Age group & 1.569 & 1.569 & 2.641 & 0.109 \\
\cline { 2 - 7 } & Gender*Age Group & 0.182 & 0.182 & 0.306 & 0.582 \\
\hline \multirow{3}{*}{ PMI } & Gender & 0.003 & 0.003 & 1.057 & 0.307 \\
\cline { 2 - 7 } & Age group & 0.001 & 0.001 & 0.389 & 0.535 \\
\cline { 2 - 7 } & Gender*Age Group & 0.002 & 0.002 & 0.818 & 0.369 \\
\hline \multirow{3}{*}{ ABL } & Gender & 0.024 & 0.024 & 1.287 & 0.260 \\
\cline { 2 - 7 } & Age group & 0.076 & 0.076 & 4.135 & 0.046 \\
\cline { 2 - 7 } & Gender*Age Group & 0.012 & 0.012 & 0.665 & 0.047 \\
\hline
\end{tabular}




\begin{tabular}{|l|l|l|l|l|l|}
\hline \multirow{2}{*}{ premolar } & Age group & 72.437 & 72.437 & 7.841 & $0.007 *$ \\
\cline { 2 - 6 } & Gender*Age Group & 1.824 & 1.824 & 0.197 & 0.658 \\
\hline \multirow{3}{*}{ Height in molar } & Gender & 94.429 & 94.429 & 10.382 & $0.002^{*}$ \\
\cline { 2 - 7 } & Age group & 78.947 & 78.947 & 8.680 & $0.004^{*}$ \\
\cline { 2 - 7 } & Gender*Age Group & 0.182 & 0.182 & 0.020 & 0.888 \\
\hline
\end{tabular}

*de notes significance

Graph 1:- Distribution of Males according to Mandibular Cortical Index (MCI)

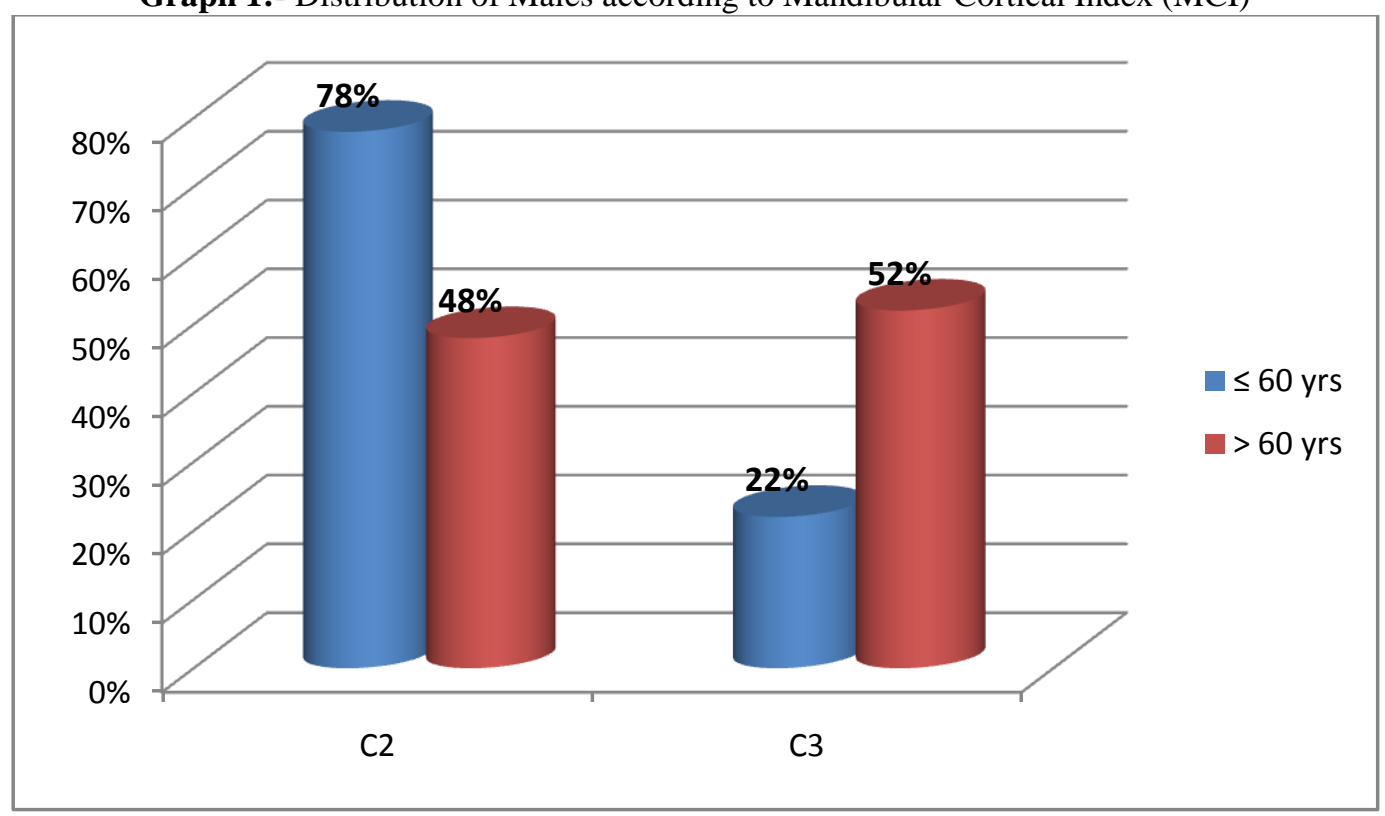

Graph 2:- Distribution of Females according to Mandibular Cortical Index (MCI)

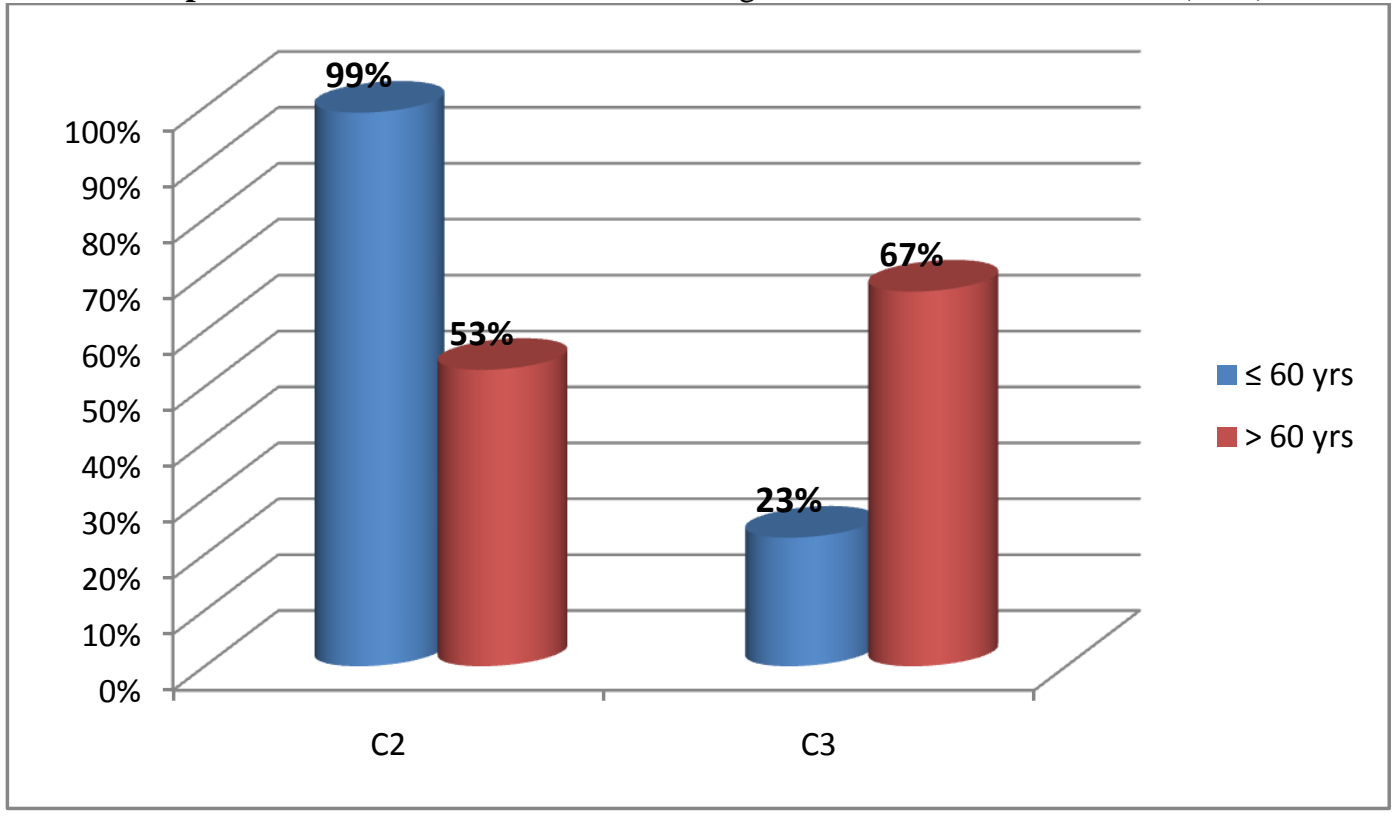


Graph 3:- Estimated marginal means of Mandibular Cortical Width (MCW)

Estimated Marginal Means of MCW

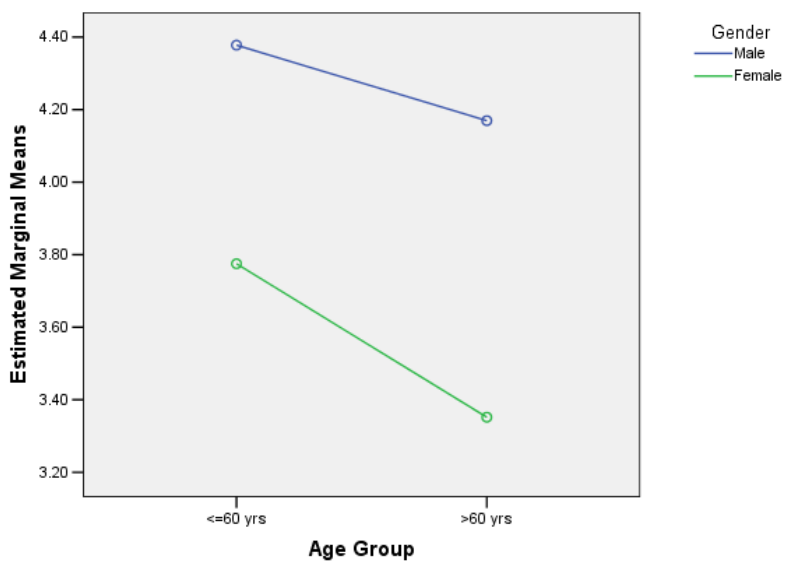

Graph 4:- Estimated marginal means of Panoramic Manibular Index (PMI)

Estimated Marginal Means of PMI

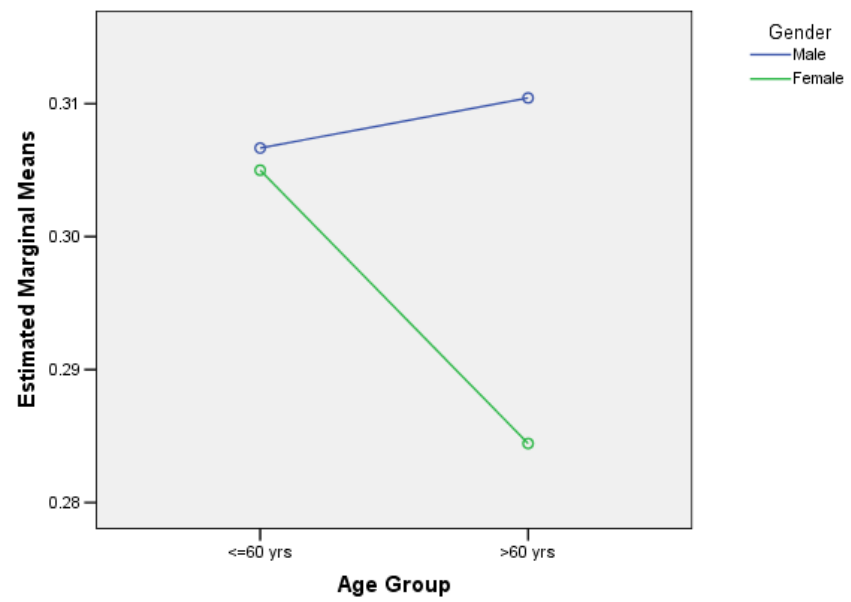

Graph 5:- Estimated marginal means of Alveolar Bone Loss (ABL) Estimated Marginal Means of ABL

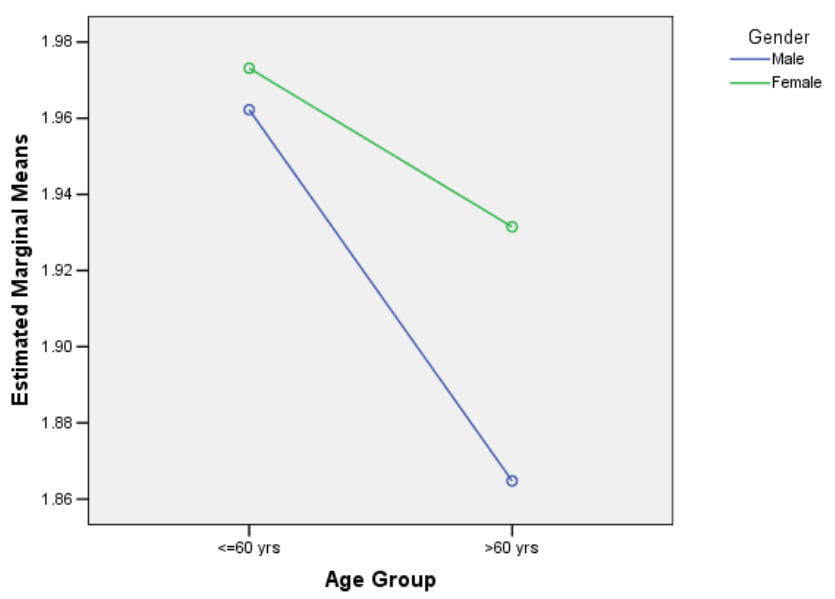


Graph 6:- Estimated marginal means of Height in Premolar (Hp) Estimated Marginal Means of Height in Premolar

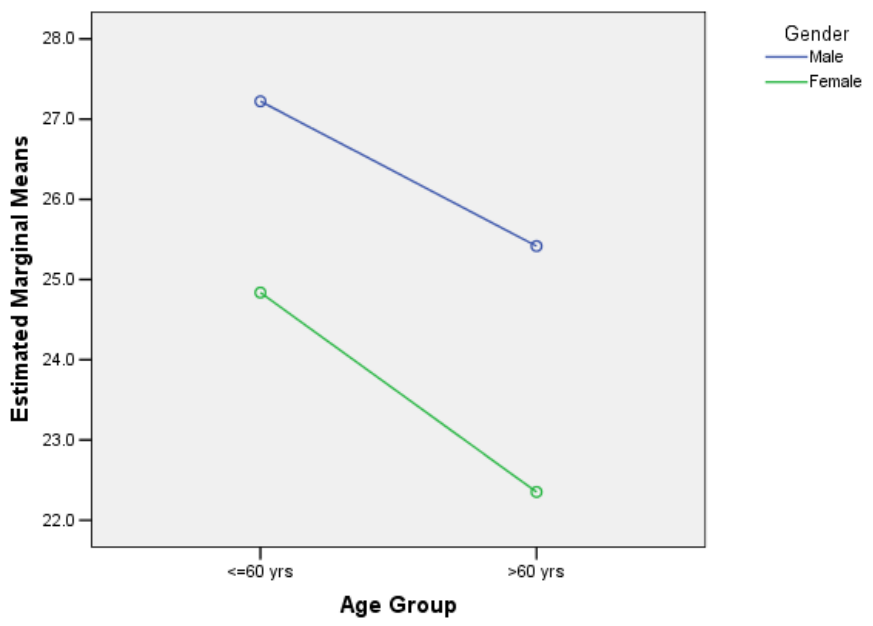

Graph 7:- Estimated marginal means of Height in Molar (Hm) Estimated Marginal Means of Height in Molar
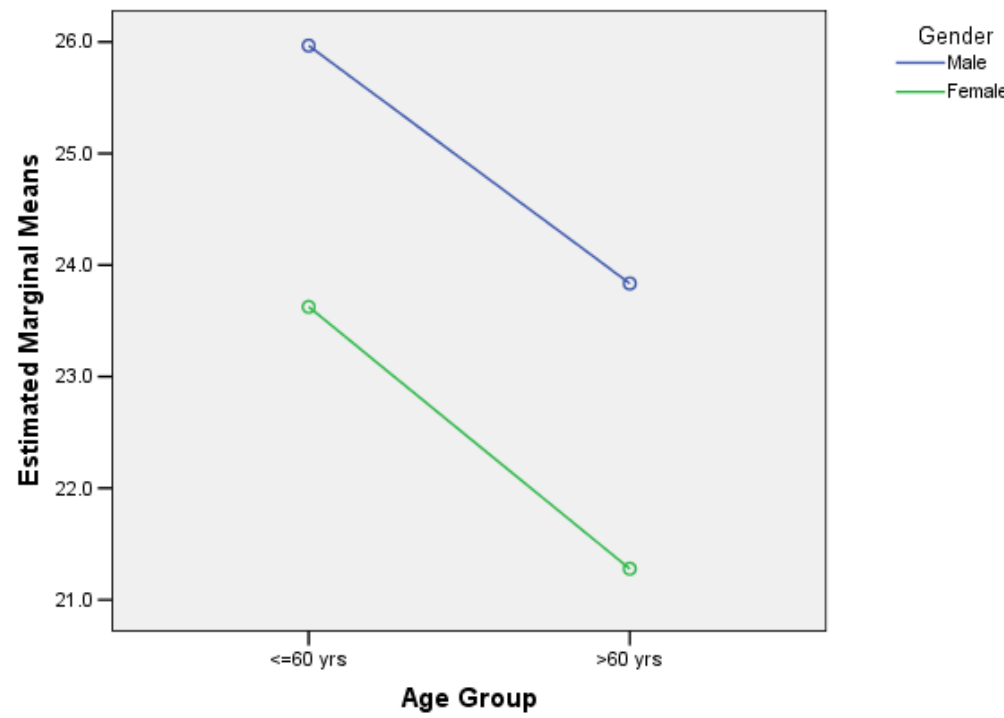

\section{Discussion:-}

The present study provides new findings on the effects of age and gender on radiomorphometric indices, ABL and bone heights in the first premolar and molar region, all in a group of completely edentulous individuals. Alveolar atrophy after the removal of teeth and the presence of tooth components in both the upper and lower jaws of edentulous patients has always been topics of discussion for dentists. This study attempted to assess the diagnostic validity of panoramic radiomorphometric indices to investigate the influence of age and gender on the mandibular cortical index, panoramic mandibular index, and mandibular cortical width, as well as alveolar bone loss and bone heights in the first premolar and molar region as all these factors have implications on treatment planning, with special regard to reconstructive procedures, subsequent implant treatment, and removable complete dentures.

Previous studies showed that minor anteroposterior shifts and tilts are associated with small variations (less than $2 \%$ ) in vertical measurements. In the present study, all measurements were reduced to the original size of the mandibular features, according to the magnification of the panoramic machine used i.e., at correction of $1.27 \%$ magnification. This compensation allowed for comparison with other studies, because different panoramic machines 
have different magnification factors. Additionally, a study ${ }^{63}$ showed that mandibular angular measurements in panoramic radiographs revealed a high degree of accuracy when proper patient positioning was achieved.

Recent studies ${ }^{18,41}$ indicate that dental panoramic radiography may be one of the tools for detecting a high risk of osteoporotic fracture. In light of these observations, this study attempted to investigate the influence of age and gender on the radiomorphometric indices which included mandibular cortical index, panoramic mandibular index, and mandibular cortical width, as well as alveolar bone loss and bone height using panoramic radiographs of edentulous patients.

\section{Mandibular Cortical Index (MCI):-}

MCI is a simple, qualitative, 3-point index with fairly good reproducibility. In the present study, only C2 and C3 categories were observed in the study group of edentulous patients. This may be attributable to the fact that the group of selected patients was relatively older, in comparison to the age of ${ }^{30}$, when the first signs of bone loss start to manifest radiographically. ${ }^{6}$

The association between MCI and age group was not statistically significant in males. However in females, the association between MCI and age group was found to be statistically significant. Females in $\leq 60$ yrs age group are found to be more associated with $\mathrm{C} 2$ whereas females in $>60$ yrs age group are found to be more associated with $\mathrm{C} 3$. The result in the present study was found to be in accordance with the study carried out by Knezovic $\mathrm{Z}$ et al. ${ }^{39}$ which stated that the age-related distribution of MCI showed an age-related increase in the numbers of individuals with C3 cortex appearance, and a significantly higher incidence of women who had C3 cortexes in an older age group and no difference was found in the distribution of men and women between MCI categories C2 and C3.

In the study conducted by Yuzugullu B et al. ${ }^{54}$ (2009) only 2 categories of MCI (C2/56.4\% and C3/43.6\%) were detected. There were no significant differences in $\mathrm{C} 2$ and $\mathrm{C} 3$ categories of MCI between age groups in men. Category $\mathrm{C} 2$ was more frequently seen in age groups of $\leq 60$, and category $\mathrm{C} 3$ was more frequently observed in age groups of $>60$ in women. When compared to our study the MCI categories were found to be similar to the above study. However, Taguchi et al ${ }^{32}$ identified a far greater proportion of $\mathrm{C} 1$ cortices in their study of 124 Japanese women in a broad age band ( $33 \pm 68$ years). This may reflect ethnic differences or a difference in the interpretation of the definitions of the MCI groups.

\section{Mandibular Cortical Width (MCW):-}

In the present study, the difference between males and females with respect to mean Mandibular cortical width is found to be statistically significant $(\mathrm{P}<0.001)$ indicating that gender is a significant factor influencing $\mathrm{MCW}$. It was found that mean MCW values did not change as age increased in men, the mean MCW values decreased significantly with age in women. The results in the current study for the mean values of MCW demonstrate an agerelated decrease in women which was in agreement with the results reported by previous studies. ${ }^{38,44,54}$

The results by Knezovic $\mathrm{Z}$ et al. ${ }^{39}$ suggested a general decrease of MCW for both genders until the age of 75 , when the values begin to decrease sharply for women compared to men. No differences with dental status were assessed. In another study by Robert et al. ${ }^{59}$ there was pattern of decrease in mandibular cortical width in women after the age of 42.5 years and in men there was slow linear decrease in MCW after age of 36 years. Only a few studies ${ }^{39,44,52}$ have evaluated the changes in MCW for men. The present study revealed that men showed a stable profile concerning $\mathrm{MCW}$ values, irrespective of an increase in age.

\section{PMI (Panoramic Mandibular Index):-}

Horner and Devlin ${ }^{37}$ have shown that the panoramic mandibular index can be used for evaluation of osteoporosis status however, he also suggested that the PMI has no significant advantage over the MCW whereas, Drozdzowska et al. ${ }^{64}$ concluded that the PMI might be used as an indicator of bone mineral changes when PMI values deviate markedly from the mean.

According to Benson et al. ${ }^{29}$ mean panoramic mandibular index values increase in the elderly. Previous studies ${ }^{29,38}$ about PMI values that have been performed primarily on women have found PMI values between 0.31 to 0.38 which are higher than the mean value of 0.27 to 0.29 found in present study. These differences may not only be due to ethnic origins, but may arise due to the inclusion of partially edentulous patients, in addition to completely edentulous individuals. The present mean PMI values for edentulous patients agree with those of Gulsahiet al. ${ }^{52}$ who 
reported mean PMI values of 0.30, 0.32, and 0.22 for $\mathrm{C} 1, \mathrm{C} 2$, and C3 categories, respectively, in a large, mixed, study population. In the present study the mean PMI values for women were found to be 0.27 to 0.29 and for men it was 0.31 which was in accordance with the studies done by Yuzugullu B et al. ${ }^{54}$ and Estin et al. ${ }^{57}$

\section{Alveolar bone loss (ABL):-}

In the present study the alveolar bone loss in the edentulous mandible was more pronounced in women than in men. Ortmanet al. ${ }^{65}$ and Baat et al. ${ }^{66}$ reported similar results. Similarly in the study done by Humphries et al. ${ }^{28}$ it was found that the age of the subject had a significant effect on residual alveolar ridge resorption in women, but not in men. Some clinicians have observed that alveolar ridge reduction occurs quickly following the menopause and is accompanied by a more generalized skeletal osteoporosis. However according to study done by Yuzugulluet al. ${ }^{54}$ it was found that ABL was not affected by age according to gender. This finding was in agreement with the results of Soikkonenet al. ${ }^{21}$ who concluded that in both genders, ABL does not increase significantly with age but in a study done by Cagri et al. ${ }^{58}$ it was found that the decrease in the height of the edentulous mandible was more pronounced in women than in men. This may be due to the reason that in postmenopausal women, deficiency of estrogen hormone accelerates skeletal bone loss and may result in rapid alveolar bone resorption. ${ }^{9}$

\section{Height in premolar and Molar region (Hp and Hm):-}

In the present study the measurement value of the mandible at first premolar and first molar regions were greater in men than women, which was in agreement with Guler et al. ${ }^{46}$ and Saglam. ${ }^{40}$ Residual ridge resorption is usually more rapid in the premolar and molar region than the anterior region of the mandible because of the lower position of the reversal line in the posterior region. ${ }^{13}$ The reversal line on the lingual side occurs along the mylohyoid ridge, which is the limit between the resorptive alveolar field and depository field of the basal bone. ${ }^{13}$

However Yuzugullu et al. ${ }^{54}$ also evaluated the heights in premolar and molar region and concluded that the heights were similar in men and women, in contrast to the findings of Guler et al. ${ }^{46}$ who found that measurements of vertical height in the edentulous women were lower than that of the men which may be due to parameters such as general health, denture wearing habits, nutrition, or medication intake were not included, which may have affected the outcome related to gender. According to the results of Xieet al. ${ }^{35}$ and Mercier ${ }^{13}$ the most pronounced percentage reduction in total height of the mandibular body was found at the first premolar and first molar sites. In the present study, the findings related to the edentulous mandible were similar to these studies although no comparison was made between dentate and edentulous mandible.

\section{Conclusion:-}

1. Category $\mathrm{C} 3$ of the mandibular cortical index, in which the cortical layer forms clearly porous heavy endosteal cortical residues, was more frequently seen in women over 60 years in age whereas, Category C2 was more frequently seen in women below 60 years. However the association between MCI and age group was not statistically significant in males.

2. The values of mean cortical width $(\mathrm{MCW})$ at the mental foramen region decreased significantly with age in women $(\mathrm{P}<0.001)$.

3. The ratio of the thickness of the mandibular cortex to the distance between the mental foramen and the inferior mandibular cortex (PMI), was not affected by gender or age.

4. In the present study the measurement value of the mandible at first premolar and first molar regions were greater in men than women.

5. In this study the alveolar bone loss in the edentulous mandible was more pronounced in women than in men.

\section{Refrences:-}

1. Von W N. General and oral aspects of osteoporosis: a review. Clin Oral Investig2001; 5: $71-82$.

2. Atwood DA. Some clinical factors related to rate of resorption of residual ridges. J Prosthet Dent 2001; 86: 119125

3. Wyatt CLL. The effect of prosthodontic treatment on alveolar bone loss: A review of the literature. J Prosthet Dent 1998; 80:362-6.

4. Knezovic Z D, Celebic A. Mandibular bone mineral density changes in complete and removable partial denture wearers: a 6 - month follow-up study. Int J Prosthodont 2003; 16:661-5.

5. Mangos JF. The healing of extraction wounds. An experimental study based on microscopic and radiographic investigations. Br Dent J 1959;71:10-7. 
6. Heersche JN, Bellows CG, Ishida Y. The decrease in bone mass associated with aging and menopause. J Prosthet Dent 1998;79:14-6.

7. Bianchi A, Sanfilippo F. Osteoporosis: the effect on mandibular bone resorption and therapeutic possibilities by means of implant prostheses. Int J Periodontics Restorative Dent 2002;22:231-9.

8. Carlsson GE, Persson G. Morphologic changes of the mandible after extraction and wearing of dentures. A longitudinal, clinical, and x-ray cephalometric study covering 5 years. Odontol Revy 1967;18:27-54.

9. Devlin H, Ferguson MW. Alveolar ridge resorption and mandibular atrophy.A review of the role of local and systemic factors. Br Dent J 1991;170:101-4.

10. Atwood DA. Reduction of residual ridges: a major oral disease entity. J Prosthet Dent 1971;26:266-79.

11. Tallgren A, Lang BR, Walker GF, Ash MM. Roentgen cephalometric analysis of ridge resorption and changes in jaw and occlusal relationships in immediate complete denture wearers. J Oral Rehabil 1980;7:77-94.

12. Bairam LR, Miller WA. Mandible bone resorption as determined from panoramic radiographs in edentulous male individuals aged 25-80 years. Gerodontology 1994;11:805.

13. Mercier P. Ridge reconstruction with hydroxylapatite. Part 1.Anatomy of the residual ridge. Oral Surg Oral Med Oral Pathol 1988;65:505-10.

14. Carlsson GE, Haraldson T. Fundamental aspects of mandibular atrophy. In: Worthington P, Branemark PI. Advanced osseointegration surgery.Applications in the maxillofacial region. Chicago Quintessence; 1992:10918.

15. Narhi TO, Ettinger RL, Lam EW. Radiographic findings, ridge resorption, and subjective complaints of complete denture patients.Int J Prosthodont 1997;10:183-9.

16. Xie Q, Ainamo A, Tilvis R. Association of residual ridge resorption with systemic factors in home-living elderly subjects. ActaOdontolScand 1997;55:299-305.

17. Klemetti E, Kolmakov S, Kroger H. Pantomography in assessment of the osteoporosis risk group. Scand J Dent Res 1994;102:68-72.

18. Taguchi A, Tsuda M, Ohtsuka M, Kodama I, Sanada M, Nakamoto T. Use of dental panoramic radiographs in identifying younger postmenopausal women with osteoporosis. OsteoporosInt 2006;17:387-94.

19. Devlin H, Allen P, Graham J, Jacobs R, Nicopoulou K, Lindh C et al The role of the dental surgeon in detecting osteoporosis: the OSTEODENT study. Br Dent J 2008;204(10):16

20. Horner K, Devlin H, Alsop CW, Hodgkinson IM, Adams JE. Mandibular bone mineral density as a predictor of skeletal osteoporosis. Br J Radiol 1996;69:1019-25.

21. Soikkonen K, Ainamo A, Xie Q. Height of the residual ridge and radiographic appearance of bony structure in the jaws of clinically edentulous elderly people. J Oral Rehabil 1996;23:470-5.

22. G. V. Packota, J. N. Hoover, B. D. Neufeld. A study of the height of intact alveolar bone on panoramic radiographs of adult patients. J Prosthet Dent 1998;60:504-508

23. Carlsson GE, Ragnarson N, Astrand P. Changes in height of the alveolar process in edentulous segments. A longitudinal clinical and radiographic study of full upper denture cases with residual lower anteriors.OdontTidskr 1967;75:193-208.

24. Mercier P, Lafontant R. Residual alveolar ridge atrophy: classification and influence of facial morphology. J Prosthet Dent 1979;41:90-100.

25. Wical KE, Swoope CC. Studies of residual ridge resorption. Part I. Use of panoramic radiographs for evaluation and classification of mandibular resorption. J Prosthet Dent 1974;32:7-12.

26. Bras J, Ooij CP, Abraham L, Kusen GJ, Wilmink JM. Radiographic interpretation of the mandibular angular cortex: A diagnostic tool in metabolic bone loss: Part I. Normal state. Oral Surg Oral Med Oral Pathol 1982;53:541-545.

27. Wilding RJ, Levin I, Pepper R. The use of panoramic radiographs to measure alveolar bone areas.J Oral Rehabil. 1987;14(6):557-67.

28. Humphries S, Devlin H, Worthington H. A radiographic investigation into bone resorption of mandibular alveolar bone in elderly edentulous adults. J Dent 1989;17:94-96

29. Byron W. Benson, Thomas J. Prihoda, Birgit J. Glass. Variations in adult cortical bone mass as measured by a panoramic mandibular index. Oral Surg Oral Med Oral Pathol 1991;71:349-356.

30. Leong IT, Slabbert JC, Becker PJ. The value of radiographic predictors of the rate of mandibular residual ridge resorption. J Prosthet Dent 1992;68:69-73.

31. Karaagaçlioglu L, Ozkan P. Changes in mandibular ridge height in relation to aging and length of edentulism period. Int J Prosthodont 1994 Jul-Aug;7(4):368- 71.

32. Latifa R, William A, Miller. Mandible bone resorption as determined from panoramic radiographs in edentulous male individuals aged 25 - 80 years. Gerodontology 1994 Dec;11(2):80-5. 
33. Taguchi A, Suei Y, Ohtsuka M, Otani K, Tanimoto K, Ohtaki M. Usefulness of panoramic radiography in the diagnosis of postmenopausal osteoporosis in women. Width and morphology of inferior cortex of the mandible. DentomaxillofacRadiol 1996 Nov;25(5):263-7.

34. Klemetti E and Kolmakow S. Morphology of the mandibular cortex on panoramic radiographs as an indicator of bone quality. DentomaxillofacRadiol 1997 26: 22- 25.

35. Xie Q, Wolf J, Ainamo A. Quantitative assessment of vertical heights of maxillary and mandibular bones in panoramic radiographs of elderly dentate and edentulous subjects. ActaOdontolScand 1997 Jun;55(3):155-61.

36. Xie Q, Wolf J, Tilvis R, Ainamo A. Resorption of mandibular canal wall in the edentulous aged population. J Prosthet Dent 1997 Jun;77(6):596-600.

37. Horner K, Devlin H. The relationship between mandibular bone mineral density and panoramic radiographic measurements. J Dent 1998 May;26(4):337-43

38. Ledgerton D, Horner K, Devlin H, Worthington H. Radiomorphometric indices of the mandible in a British female population. DentomaxillofacRadiol 1999 May;28(3):173-81.

39. Knezovic ZD, Celebi CA, Lazi CB, Bauci CI, Komar D et al. Influence of age and gender on radiomorphometric indices of the mandible in removable denture wearers. CollAntropol 2002 Jun;26(1):259-66.

40. Saglam AA. The vertical heights of maxillary and mandibular bones in panoramic radiographs of dentate and edentulous subjects. Quintessence Int 2002 Jun;33(6):433-8.

41. Zlataric DK, Celebic. A Clinical bone densitometric evaluation of the mandible in removable denture wearers dependent on the morphology of the mandibular cortex. J Prosthet Dent 2003 Jul;90(1):86-91.

42. Tallgren A. The continuing reduction of the residual alveolar ridges in complete denture wearers: a mixedlongitudinal study covering 25 years. J Prosthet Dent 2003;89(5):427-35.

43. Xie QF, Ainamo A. Correlation of gonial angle size with cortical thickness, height of the mandibular residual body, and duration of edentulism. J Prosthet Dent 2004 May;91(5):477-82.

44. Dutra V, Yang J, Devlin H, Susin C. Radiomorphometric indices and their relation to gender, age, and dental status. Oral Surg Oral Med Oral Pathol Oral RadiolEndod2005;99(4):479-84.

45. Lee K, Taguchi A, Ishii K, Suei Y, Fujita M, Nakamoto T, Ohtsuka M, Sanada M, Tsuda M, Ohama K, Tanimoto K, White SC. Visual assessment of the mandibular cortex on panoramic radiographs to identify postmenopausal women with low bone mineral densities. Oral Surg Oral Med OralPathol Oral RadiolEndod 2005;100(2):226-31.

46. Guler AU, Sumer M, Sumer P, Biçer I. The evaluation of vertical heights of maxillary and mandibular bones and the location of anatomic landmarks in panoramic radiographs of edentulous patients for implant dentistry. $\mathrm{J}$ Oral Rehabil2005 ;32(10):741-6.

47. Dutra V, Devlin H, Susin C, Yang J, Horner K et al. Mandibular morphological changes in low bone mass edentulous females: evaluation of panoramic radiographs. Oral Surg Oral Med OralPatholOral RadiolEndod2006;102(5):663-8.

48. Devlin H, Horner K. A study to assess the relative influence of age and edentulousness upon mandibular bone mineral density in female subjects. Oral Surg Oral Med Oral Pathol Oral RadiolEndod 2007;104:117-21.

49. Devlin H, Karayianni K, Mitsea A, Jacobs R, Lindh C, Vander P et al. Diagnosing osteoporosis by using dental panoramic radiographs: the OSTEODENT project. Oral Surg Oral Med Oral Pathol Oral RadiolEndod2007;104(6):821-8.

50. Alkurt MT, Peker I, Sanal O. Assessment of repeatability and reproducibility of mental and panoramic mandibular indices on digital panoramic images. Int Dent J 2007 Dec;57(6):433-8.

51. Vlasiadis KZ, Skouteris CA, Velegrakis GA,Fragouli I, Neratzoulakis JM, Damilakis J, Koumantakis EE. Mandibular radiomorphometric measurements as indicators of possible osteoporosis in postmenopausal women.Maturitas2007;58(3):226-35.

52. Gulsahi A, Yuzugullu B, Imirzalioglu P, Genc Y. Assessment of panoramic radiomorphometric indices in Turkish patients of different age groups, gender and dental status. DentomaxillofacRadiol2008;37(5):288-92.

53. Gulsahi A, Ozden S, Ilker A, OzlemN, Candan S and Yasemin G. The relationship between panoramic radiomorphometric indices and the femoral bone mineral density of edentulous patients Oral Radiology 2009;25 (1):47-52.

54. Yuzugullu B, Gulsahi A and Imirzalioglu P. Radiomorphometric indices and their relation to alveolar bone loss in completely edentulous Turkish patients: A retrospective study. J Prosthet Dent 2009;101:160-165.

55. Leite AF, Figueiredo PT, Guia CM, Melo NS, de Paula AP. Correlations between seven panoramic radiomorphometric indices and bone mineral density in postmenopausal women. Oral Surg Oral Med Oral Pathol Oral RadiolEndod2010;109(3):449-56. 
56. Dagistan S and Bilge OM. Comparison of antegonial index, mental index, panoramicmandibular index and mandibular cortical index values in the panoramic radiographs of normal males and male patients with osteoporosis. DentomaxillofacRadiol 2010; 39:290 -294.

57. Hastar E, Huseyin H, Orhan H. Evaluation of Mental Index, Mandibular Cortical Index and Panoramic Mandibular Index on Dental Panoramic Radiographs in the Elderly. Eur J Dent 2011;5:60-67.

58. CagriU,Cihan B, Ismail S, Ali MA, Yusuf ZA. Bone height measurement of maxillary and mandibular bones in panoramic radiographs of edentulous patients. J ClinExp Dent 2011;3(1):5-9.

59. Roberts M, Yuan J, Graham J, Jacobs R and Devlin H. Changes in mandibular cortical width measurements with age in men and women. Osteoporosis International 2011;22(6):1915-1925.

60. Imirzalioglu P, Yuzugullu B, Gulsahi A. Correlation between residual ridge resorption and radiomorphometric indices. Gerodontology 2011;10:55-58.

61. Kim YK, Park JY, Kim SG, Kim JS and Kim JD. Magnification rate of digital panoramic radiographs and its effectiveness for pre-operative assessment of dental implants.DentomaxillofacRadiol 2011;40:76-83.

62. Mostafa, RA, Ashiry E, Mohamed K, Farid, Mary M. Effect of age, sex, and dental status on mental and panoramic mandibular indices of the mandible: a retrospective study. Egyptian Journal of Oral \&Maxillofac Surgery 2011;2(1):22 -26.

63. Drozdzowska, Pluskiewicz W, Tarnawska B. Panoramic-based mandibular indices in relation to mandibular bone mineral density and skeletal status assessed by dual energy X-ray absorptiometry and quantitative ultrasound DentomaxillofacRadiol 2002;31: 361-367.

64. Ortman LF, Hausmann E, Dunford RG. Skeletal osteopenia and residual ridge resorption. J Prosthet Dent 1989;61: 321-5.

65. Baat C, Kalk W, Vant HM. Factors connected with alveolar bone resorption among institutionalized elderly people. Community Dent Oral Epidemiol 1993;21: 317-20. 